\title{
Thymic Epithelial Stem Cell
}

National Cancer Institute

\section{Source}

National Cancer Institute. Thymic Epithelial Stem Cell. NCI Thesaurus. Code C45723.

An epithelial cell that exists in the early fetal thymus that has the capacity to give rise to both cortical and medullary thymic epithelium. 